\title{
Core-shell pure collagen threads extruded from highly concentrated solutions promote colonization and differentiation of $\mathrm{C} 3 \mathrm{H} 10 \mathrm{~T} 1 / 2$ cells
}

Authors: Lise Picaut ${ }^{1,2}$, Léa Trichet ${ }^{2}$, Christophe Hélary ${ }^{2}$, Guillaume Ducourthial ${ }^{3}$, MarieAnge Bonnin ${ }^{4}$, Bernard Haye ${ }^{2}$, Olivier Ronsin ${ }^{1}$, Marie-Claire Schanne-Klein ${ }^{3}$, Delphine Duprez $^{4}$, Tristan Baumberger ${ }^{1}$ and Gervaise Mosser ${ }^{2}$.

\section{Affiliations :}

1 Institut des Nanosciences de Paris, Sorbonne-Université, UPMC Univ Paris 6 and CNRSUMR 7588, F-75005 Paris, France,

2 Sorbonne-Université, Laboratoire de Chimie de la Matière Condensée de Paris, UPMC Univ Paris 6, CNRS-UMR 7574, F-75005 Paris,

3 Laboratoire d'Optique et Biosciences, Ecole Polytechnique, CNRS, INSERM, IP Paris, F91128 Palaiseau, France

4 Sorbonne Université, CNRS, Institut Biologie Paris Seine, IBPS-UMR 7622, Developmental Biology Laboratory, Inserm U1156, F-75005 Paris, France

Corresponding author: Gervaise.Mosser@upmc.fr

Number of Pages : 8

Number of figures : 7

Number of tables : 1 


\section{Supplementary Data.}

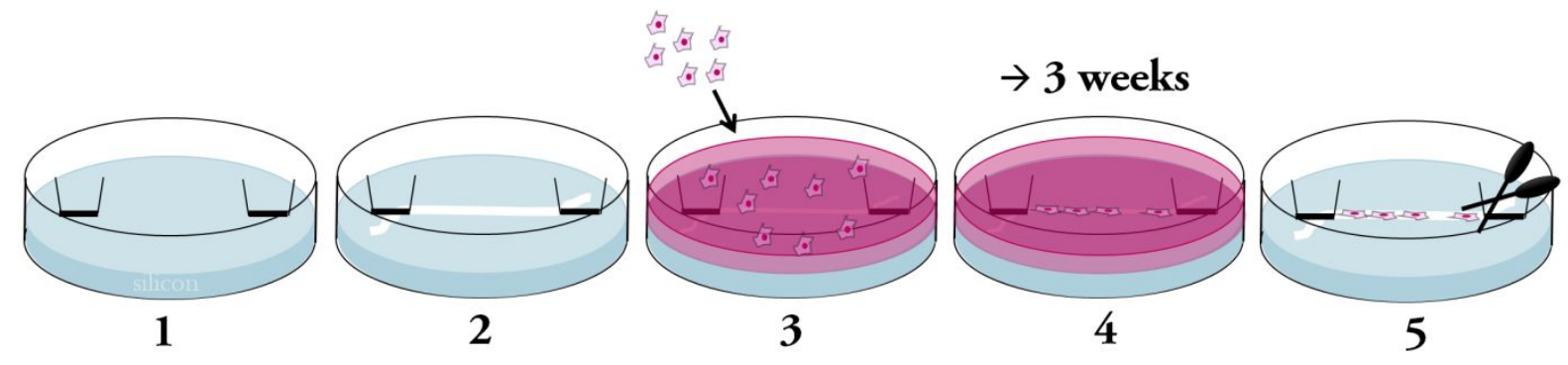

Figure SI-1: Protocol of cell culture on collagen threads under tension. 1) 6-well plate bases are covered with silicon gel (SYLGARD) and silk sutures are pinned with needles. 2) Threads are put under tension between the two sutures and 3) C3H10 T1/2 cells are added. 4) After 3 weeks of culture, 5) extremities are cut and threads are observed by different techniques. 


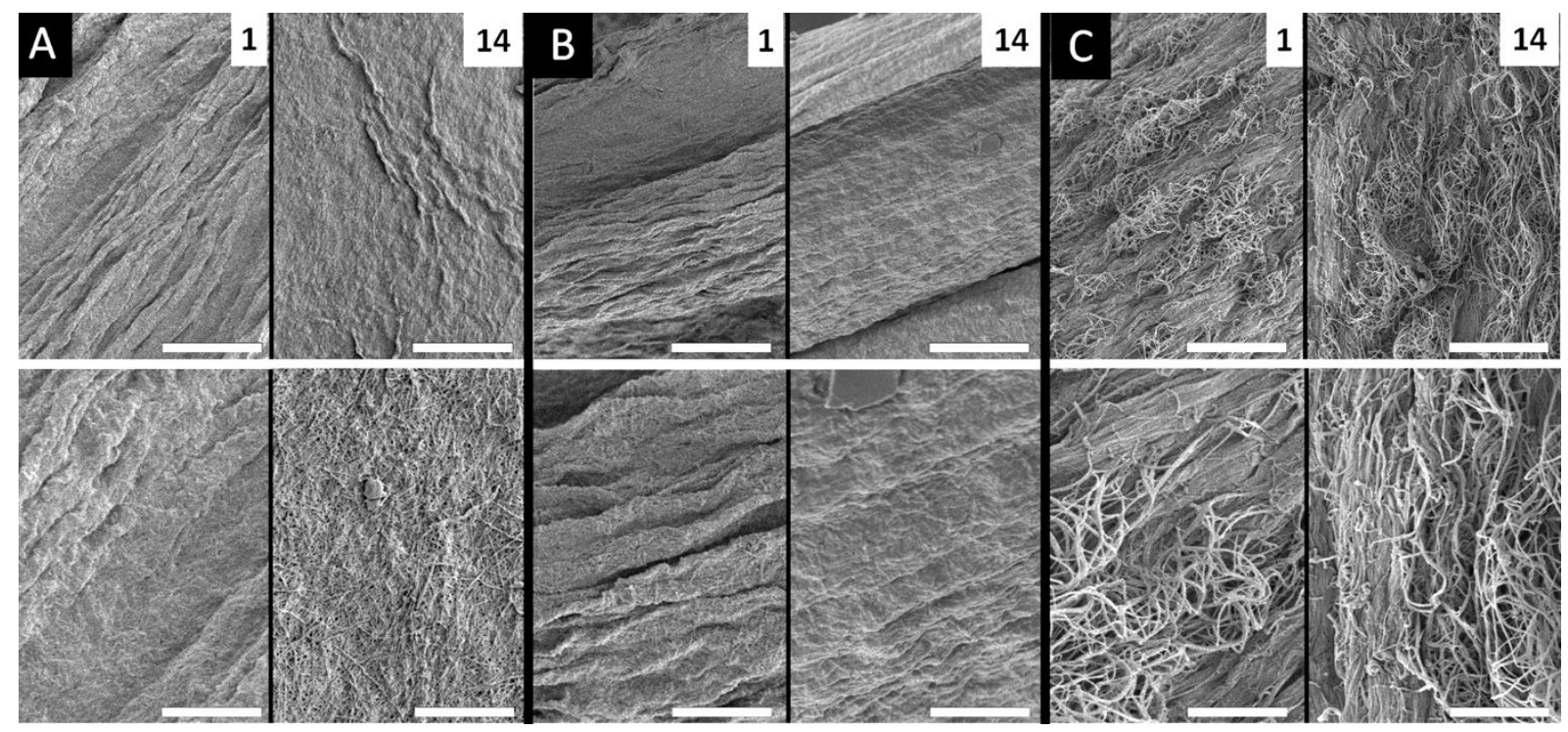

Figure SI-2: SEM images of threads surface at A) $15 \mathrm{mg} / \mathrm{mL}$, B) $30 \mathrm{mg} / \mathrm{mL}$, C) $60 \mathrm{mg} / \mathrm{mL}$ at day 1 and 14. A. appears flatter than B. or C. where a more pronounced roughness is observed. TOP scale bars $=$ $25 \mu \mathrm{m}$, BOTTOM scale bars $=5 \mu \mathrm{m}$. 

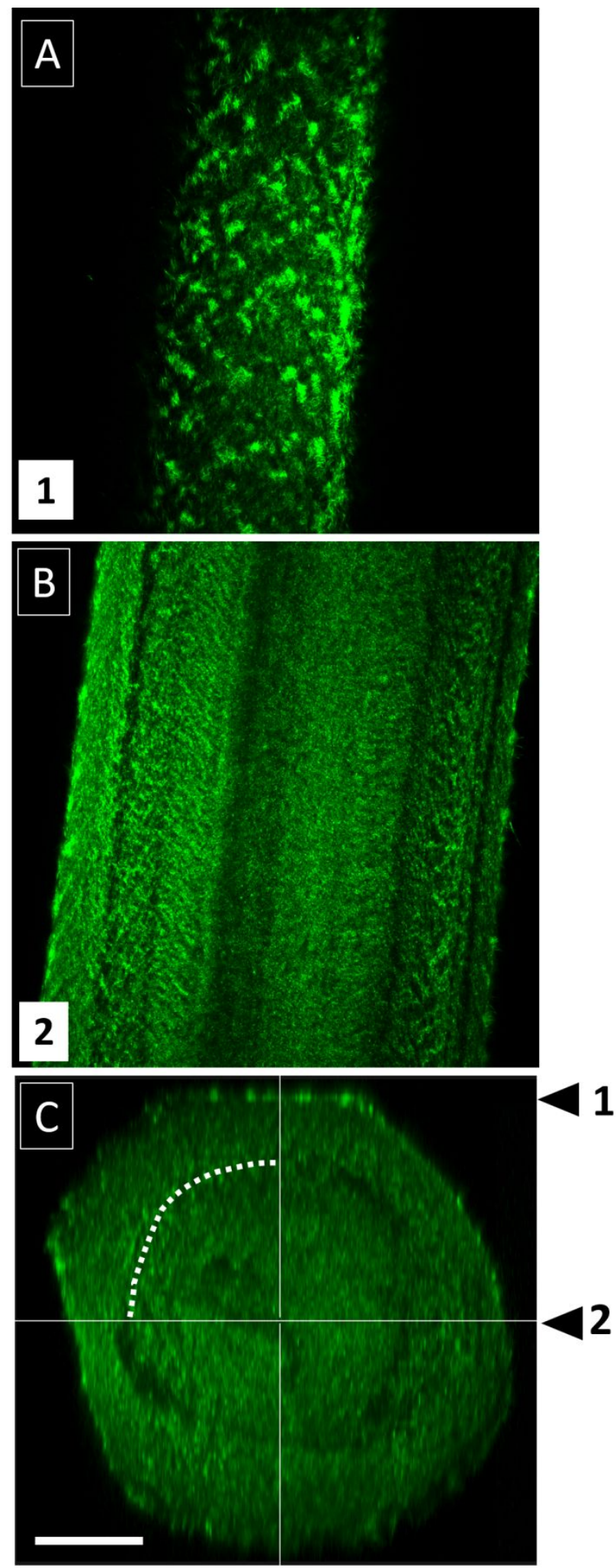

Figure SI-3: SHG imaging of the full thickness of collagen threads at $60 \mathrm{mg} / \mathrm{mL}$ after 2 weeks in PBS 5X. A. and B. correspond to transverse images acquired at the depths $-1-$ and -2indicated by the arrowheads in the cross-section reconstruction $\mathrm{C}$. At the surface, clusters of fibrillary collagen are observed (A-1-). (B-2-) shows different textures defining two main regions seen in $(C)$ : the shell and the core separated by an area where the SHG signal is almost zero (black dashed line). Scale bars $=100 \mu \mathrm{m}$. 

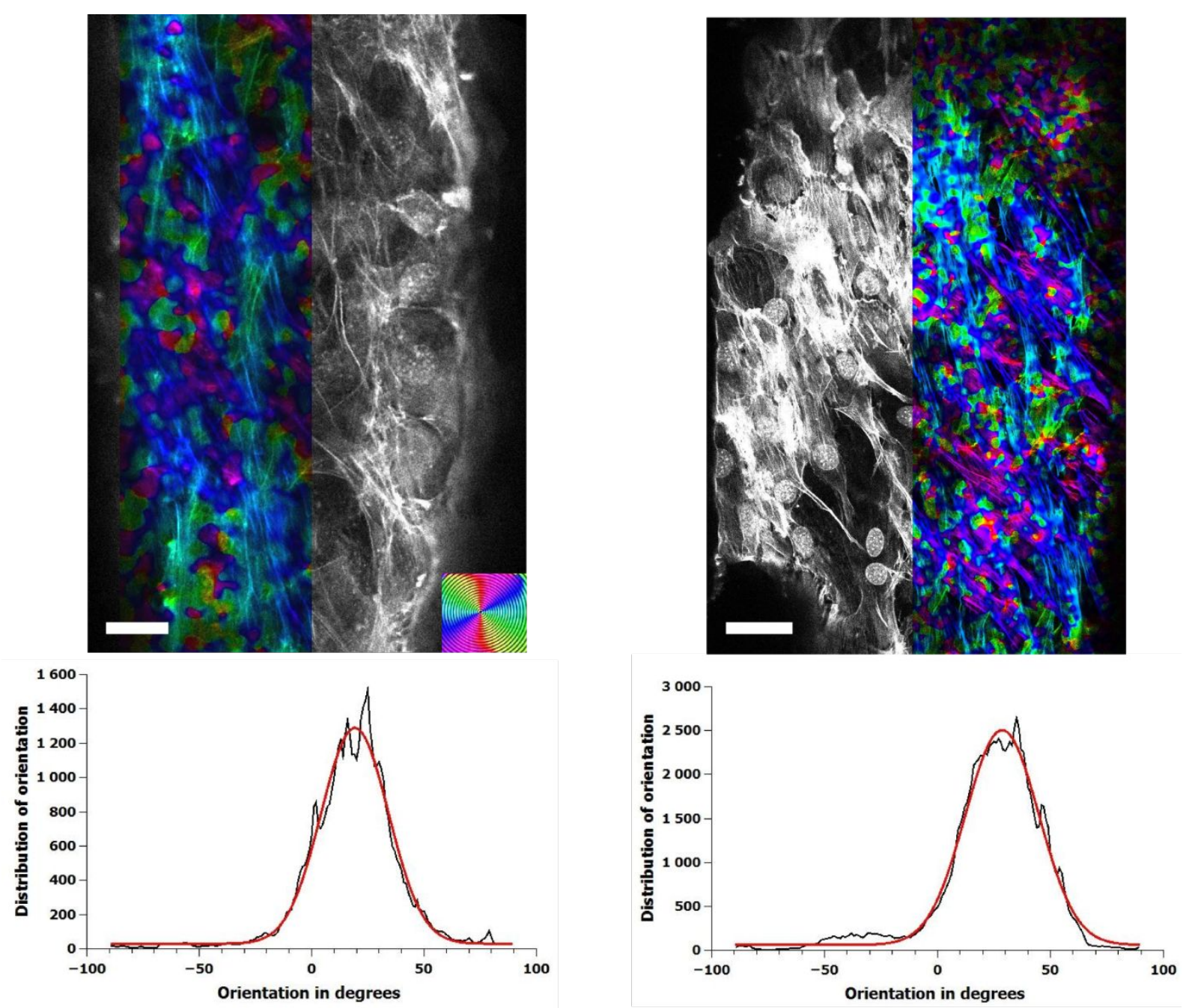

Figure SI-4: Examples of $\mathrm{C} 3 \mathrm{H} 10 \mathrm{~T} 1 / 2$ cell orientation assessment by means of Orientation $\mathrm{J}$ distribution analysis of actin filaments observed with $2 \mathrm{PEF}$ microscopy on $30 \mathrm{mg} / \mathrm{mL}$ (left) and 60 $\mathrm{mg} / \mathrm{mL}$ (right) threads. (Top) Hybrid images presenting the original Alexa Fluor 488 Phalloidin signal on one side and the local orientation as indicated by the circular color wheel (insert) on the other side. (Bottom) Histograms of orientations obtained for each specific example over the entire displayed image. Scale bars $=50 \mu \mathrm{m}$. 


\section{Coll $30 \mathrm{mg} / \mathrm{mL}$}

\section{Coll $60 \mathrm{mg} / \mathrm{mL}$}
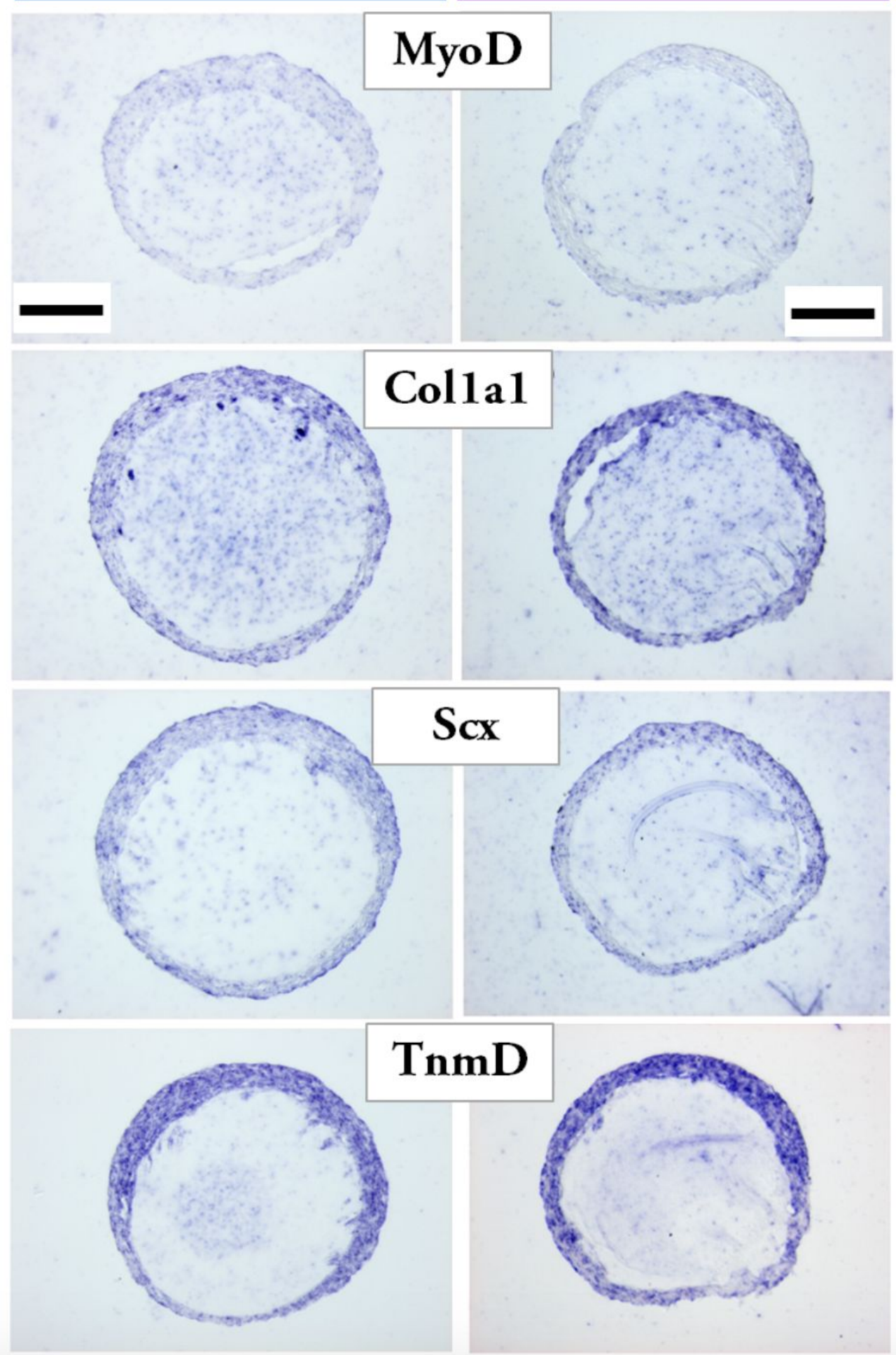

Figure SI-5: In situ hybridization on collagen threads cross-sections at 30 and $60 \mathrm{mg} / \mathrm{mL}$ after 3 weeks of culture. Tenomodulin (Tnmd) presents the strongest signal in both threads with collagen (ColIa1) coming right after. The myogenic gene $(\mathrm{MyoD})$ is not detected. Scale bar $=100 \mu \mathrm{m}$. 


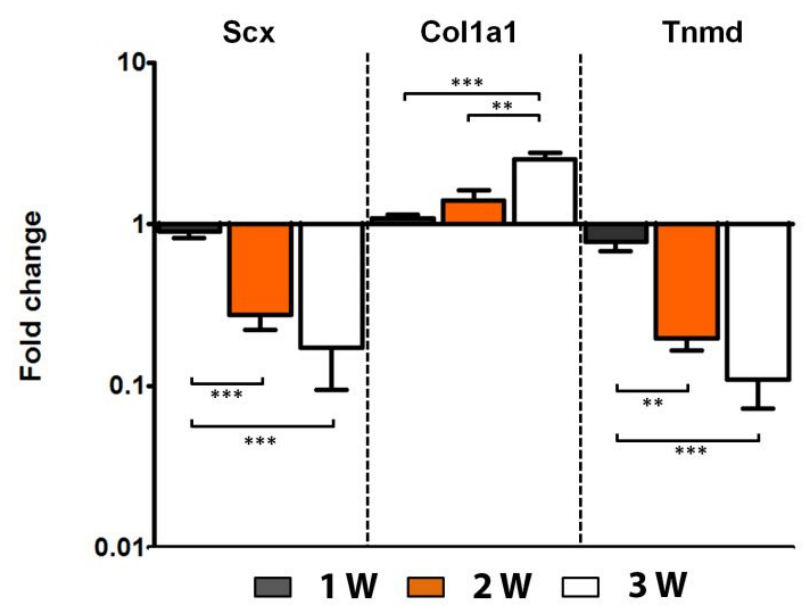

Figure SI-6: Scleraxis, collagen Ia1 and tenomodulin gene expression on $30 \mathrm{mg} / \mathrm{mL}$ collagen threads, effect of cell culture time at 1-, 2- and 3-weeks culture. ( $* \mathrm{P}<0.05, * * \mathrm{P}<0.001, * * * \mathrm{P}$ $<0.001)$. 

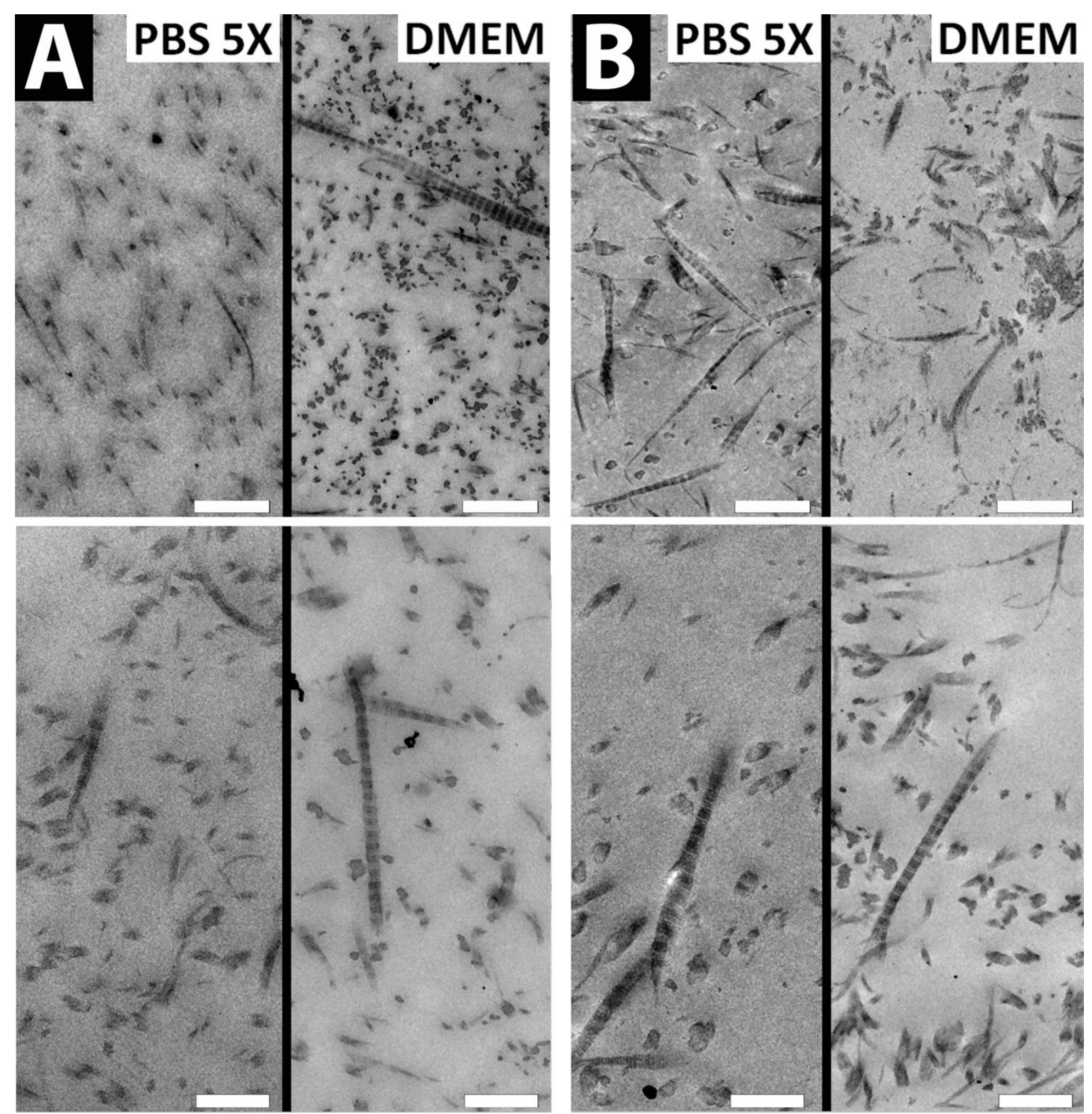

Figure SI-7: TEM images of cross-sections of collagen threads after 2 weeks in PBS 5X and after medium change to DMEM at $37^{\circ} \mathrm{C}$ for 2 weeks: at $30 \mathrm{mg} / \mathrm{mL}$ (A) and at $60 \mathrm{mg}$ (B). Top scale bars $=$ $500 \mathrm{~nm}$, bottom scale bars $=200 \mathrm{~nm}$. 


\begin{tabular}{|c|c|c|}
\hline \multicolumn{3}{|c|}{ TABLE SI-1 } \\
\hline Name & $\begin{array}{l}\text { Direction } \\
(\mathrm{F} \text { or } \mathrm{R})\end{array}$ & Sequence \\
\hline 36B4 & $\mathrm{F}$ & ACCT ССТT СТTC CAGG CTTT \\
\hline 36B4 & $\mathrm{R}$ & CTCC CACC TTGT CTCC AGTC \\
\hline Colla1 & $\mathrm{F}$ & TGGA GAGA GCAT GACC GATG \\
\hline Colla1 & $\mathrm{R}$ & GAGC CCTC GCTT CCGT ACT \\
\hline Scx & $\mathrm{F}$ & CCTT CTGC CTCA GCAA CCAG \\
\hline Scx & $\mathrm{R}$ & GGTC CAAA GTGG GGCT CTCC GTGA CT \\
\hline Tnmd & F & AACA CTTC TGGC CCGA GGTA T \\
\hline Tnmd & $\mathrm{R}$ & AAGT GTGC TCCA TGTC ATAG GTTT T \\
\hline
\end{tabular}

Table-S1: Table of primers used for the RT-q-PCR 